\title{
Reciprocated cross sucking between dairy calves after weaning off milk does not appear to negatively affect udder health or production
}

\author{
Alison Vaughan, ${ }^{*} \dagger^{1}$ Giuliana G. Miguel-Pacheco, $† \ddagger$ Anne Marie de Passillé, ${ }^{*}$ and Jeffrey Rushen* \\ *University of British Columbia, 6947 Highway 7, Agassiz, BC, VOM 1A0, Canada \\ †Applied Animal Behaviour and Animal Welfare Programme, The University of Edinburgh, Easter Bush Veterinary Centre, Roslin EH25 9RG, \\ United Kingdom \\ ¥School of Veterinary Science and Medicine, University of Nottingham, Loughborough LE12 5RD, United Kingdom
}

\begin{abstract}
Cross sucking by dairy calves occurs most commonly before weaning, but is of most concern in older animals where it has been claimed to cause mastitis and udder damage. Providing ad libitum milk allowance via a teat and gradual weaning reduces cross sucking, but low levels of this behavior still persist. Our aims were to understand why this behavior persists in some calves after weaning off milk and to examine whether individuals which are cross sucked postweaning are more likely to sustain teat injury or develop mastitis during their first lactation. Fifty-six female Holstein calves were housed in groups of 8 and fed milk, grain, and hay ad libitum from automated feeders. During weaning, milk allowance was gradually reduced according to grain intake. Cross sucking was recorded using overhead video cameras ( 5 observation periods of $72 \mathrm{~h}$ ). The effects of weaning on cross sucking were examined; to examine whether cross sucking affected udder health, all incidences of damaged quarters or clinical and subclinical mastitis in the first lactation were recorded, as was milk production. The overall level of cross sucking after weaning, at 4 to 5 mo of age, was low and a small proportion of individuals accounted for the majority of events. The duration of cross sucking that occurred at 4 to 5 mo of age was correlated with the amount of cross sucking done before and immediately after weaning. After weaning, the calves that cross sucked did so on certain calves, with the most sucked calf within each pen accounting for $73.98 \%$ of all cross-sucking events. No relationship was found between cross sucking and being cross sucked in the period before weaning but a positive correlation was found by 4 to 5 mo of age. The majority of calves reduced or ceased cross sucking after weaning. Individuals still observed to be cross sucking
\end{abstract}

Received February 24, 2015.

Accepted November 11, 2015.

${ }^{1}$ Corresponding author: alisoncvaughan@gmail.com by 4 to 5 mo of age had formed pairs with other crosssucking individuals and cross-sucking events occurred almost exclusively between these pairs. Cows that were cross sucked as heifers were no more likely to develop mastitis or have higher somatic cell count in their first lactation than those which were not involved in cross sucking. Cross sucking typically begins before weaning, but the formation of lasting pairs of reciprocal crosssucking partners after weaning may be responsible for this behavior persisting in group housed dairy calves after weaning off milk. Low levels of cross sucking did not appear to have a negative effect on udder health.

Key words: dairy calf, cross sucking, weaning, social behavior, mastitis

\section{INTRODUCTION}

Cross sucking, which involves one calf sucking on another calf, can occur in group-housed milk-fed dairy calves. Although most calves cease this behavior once weaned (Lidfors, 1993), it may sometimes continue in older animals (Keil and Langhans, 2001; Keil et al., 2001; de Passillé et al., 2011) where it is thought to cause udder deformations, mastitis, and milk loss (Lidfors and Isberg, 2003). As a result, cross sucking may contribute toward the reluctance of some farmers to adopt group housing of pre-weaned calves.

Evidence indicates that cross sucking before and during weaning may reflect inadequate milk or energy intake (Jung and Lidfors, 2001; Roth et al., 2008) and be affected by weaning method (Roth et al., 2008). Although it has been demonstrated that cross sucking can be reduced by increasing milk allowance and an appropriate outlet for sucking behavior (Jung and Lidfors, 2001), this behavior is also observed in calves provided ad libitum milk via a teat, albeit at lower intensity. Typically cross sucking is directed toward a small proportion of calves within a group (Laukkanen et al., 2010) with the result that even a low overall occurrence of this behavior may be problematic for individual animals. 
Many studies cite cross sucking among weaned calves as a risk factor for udder damage or development of mastitis in lactating cows (Špinka, 1992; Keil et al., 2000, 2001). It has been hypothesized that cross sucking may open the teat channel, allowing bacteria to enter or that cross suckers may transfer bacteria from the teats of infected individuals to uninfected heifers (Lidfors and Isberg, 2003). However, to date no studies have been conducted to test the validity of the proposed link between cross sucking and incidence of mastitis and udder damage.

Despite the fact that cross sucking is of most concern in older animals, previous studies have focused on cross sucking occurring in calves before and directly after weaning off milk (see Jensen and Holm, 2003). The link between cross sucking in milk-fed calves and that observed in older animals is supported by both epidemiological (Keil et al., 2001) and smaller scale experimental studies (de Passillé et al., 2011). Why this behavior develops and persists in some individuals but not in others is a question that remains unanswered, however, some evidence suggests the role of the recipient may be important for persistence of this behavior (Laukkanen et al., 2010).

Our first objective was to understand the factors that lead some calves to persist in cross sucking long after being weaned off milk. In particular, we examined the role of reciprocated cross sucking, which has been suggested as a contributing factor in continued cross sucking (de Passillé et al., 2011). Finally, we followed heifers through their first lactation to examine if being cross sucked had an effect on udder health or production.

\section{MATERIALS AND METHODS}

This study was conducted at the University of British Columbia's Dairy Education and Research Centre in Agassiz, BC, Canada. All experimental conditions and procedures met the requirements of the Canadian Council for Animal Care.

\section{Animals, Housing, and Management}

Female Holstein calves $(\mathrm{n}=56)$ were removed from their dam and fed $4 \mathrm{~L}$ of colostrum within $6 \mathrm{~h}$ of birth and transferred to individual concrete-floored pens $(1.22 \mathrm{~m} \times 2.44 \mathrm{~m})$ with sawdust bedding. Within the first $24 \mathrm{~h}$ of age, calves were weighed and identification ear tags attached. Ear tags were fitted with transponders that communicate with feeders to allow feed and water intakes of individual calves to be recorded. Between 1 and $5 \mathrm{~d}$ of age, calves received up to $12 \mathrm{~L}$ of pasteurized whole milk/d (i.e., ad libitum) in 2 meals (approximately 0800 and $1500 \mathrm{~h}$ ) via an artificial teat attached to the pen wall. At $6 \mathrm{~d}$ old $( \pm 1 \mathrm{~d})$, calves were moved to a group pen until 8 calves were within the pen, whereupon a new group pen was begun. Group pens consisted of a $4.74 \mathrm{~m} \times 4.64 \mathrm{~m}$ bedded area (wood shavings) and $4.74 \mathrm{~m} \times 2.48 \mathrm{~m}$ feeder area with expanded metal floor. Within each group, the maximum difference between the oldest and youngest calf was 4 wk.

The feeding area contained one automated milk feeder and one automated grain starter feeder (DeLaval CF 1000 CS Combi, Sweden), one hay feeder and one water feeder (Insentec, Marknesse, the Netherlands). The automated milk feeder provided calves with filtered and pasteurized waste milk from dairy cows at the center via an artificial teat. Grain feeders dispensed commercial calf starter mix with $17.4 \%$ protein, $6.37 \%$ fiber, and $4.38 \%$ fat content (Unifeed Ltd., Chilliwack, Canada) in 20-g portions, at a maximum rate of $9 \mathrm{~kg} / \mathrm{d}$ (i.e., ad libitum). Hay and water were freely available.

The milk and grain feeders measured the daily individual milk and grain intakes for each calf using the volume of feed dispensed. Both grain and milk feeders recorded timing, number, and duration of visits. The hay feeders and drinkers were equipped with hydraulic scales which allowed for consumption of hay and water to be measured. Data from milk and grain feeders was recorded and stored by Kalbmanager and Win_Institute programs (Foerster-Technik, Engen, Germany). Water and hay consumption was recorded by Insentec RIC-System IV TIRIS Identification Roughage/Water Version 11 UH7802 (Insentec).

Calves were weaned off milk according to starter intake. For purposes of another experiment (de Passillé and Rushen, 2012), the calves were allocated to 4 weaning treatments (low-low, low-high, high-low, high-high) according to birth order, with weaning commencing when calves had consumed the target intake of either $200 \mathrm{~g} / \mathrm{d}$ (low) or $400 \mathrm{~g} / \mathrm{d}$ (high) of starter and weaning completed when calves had consumed the target intake of either $800 \mathrm{~g} / \mathrm{d}$ (low) or 1,600 g/d (high) for 3 consecutive days. However, because we found no effect of the targets used on energy intake or on cross sucking, we do not discuss these further. Once a calf's mean grain intake over 3 consecutive days met or surpassed the first grain target, milk allowance was reduced from the full ration of $12 \mathrm{~L}$ to $9 \mathrm{~L}$. This process was repeated for the subsequent targets, with milk allowance reduced by $3 \mathrm{~L}$ for each step. Milk allowance was reduced to $0 \mathrm{~L}$ (weaned) upon achieving the final grain target. The computer was programmed to wean those calves not achieving their grain intake targets by $74 \mathrm{~d}$ old automatically, across a mean of $7 \mathrm{~d}$ (range 6-9 d). This method of weaning resulted in large differences between calves in the age and duration of weaning. Weaning 
Table 1. Experimental periods for date selection; $2 \mathrm{~d}$ selected from each period

\begin{tabular}{|c|c|c|c|c|c|c|}
\hline Before weaning & Weaning & $\begin{array}{l}\text { Postweaning } \\
\text { d } 1-3\end{array}$ & $\begin{array}{l}\text { Postweaning } \\
\text { d } 7-10\end{array}$ & $\begin{array}{l}\text { Moved to } \\
\text { heifer barn }\end{array}$ & $\begin{array}{l}\text { Heifer barn } \\
\text { d 6-7 }\end{array}$ & $\begin{array}{l}\text { Heifer barn } \\
\text { d } 41-42\end{array}$ \\
\hline $\begin{array}{l}5 \mathrm{~d} \text { before } 1 \text { st milk } \\
\text { reduction }\end{array}$ & & $\begin{array}{l}\text { First day of } 0 \text { milk } \\
\text { and following } 2 \mathrm{~d}\end{array}$ & $\begin{array}{l}7-10 \mathrm{~d} \text { after } 1 \mathrm{st} \\
\text { day of } 0 \text { milk }\end{array}$ & $\begin{array}{l}\text { (age range } \\
\text { d } 82-114 \text { ) }\end{array}$ & $\begin{array}{l}\text { Days } 6 \text { and } 7 \\
\text { in heifer barn }\end{array}$ & $\begin{array}{l}\text { Days } 41 \\
\text { and } 42 \text { in } \\
\text { heifer barn }\end{array}$ \\
\hline
\end{tabular}

began at a median age of $59 \mathrm{~d}$ [quartile $(\mathbf{Q}) 1=42 \mathrm{~d}$, $\mathrm{Q} 3=72 \mathrm{~d}]$ and lasted a median of $8 \mathrm{~d}(\mathrm{Q} 1=5 \mathrm{~d}, \mathrm{Q} 3$ $=15 \mathrm{~d})$, with weaning completed at a median age of 69 $\mathrm{d}(\mathrm{Q} 1=59 \mathrm{~d}, \mathrm{Q} 3=77 \mathrm{~d})$.

After weaning, once the youngest calf within a group had reached $87 \mathrm{~d}$ of age, the group was moved intact to a pen within an adjacent heifer barn and remained in these stable groups until they achieved breeding age (approximately $18 \mathrm{mo}$ ). The pens measured 48.8 $\mathrm{m}^{2}$ and consisted of a large raised concrete area with sawdust bedding and a concrete area containing 2 hay feeders and one grain feeder (Insentec) and a water bin. Animals were provided a standard diet of $2.5 \mathrm{~kg}$ grain with the same composition as that used in the calf barn and ad libitum hay.

\section{Measures}

Three overhead video cameras (WVBP 334, Panasonic, Osaka, Japan) were mounted above each pen in the calf and heifer barns and positioned to allow a clear view of all areas within the pen. Two recording systems were used to store and view video footage (Geovision DVR version 8.4, Taipei Headquarters, Taipei, Taiwan, and Genetec Omnicast Archive Player, Genetec Inc., Saint-Laurent, QC, Canada).

Cross sucking was defined as a calf (the actor) sucking on the navel or belly of another calf (the recipient), with the muzzle positioned under the recipient's belly, either from the left or right side or from behind, between the hind legs, and reaching far enough underneath the recipient's belly to the point where it would reach the teats or navel. The start time of a cross-sucking bout was taken as the moment when the characteristic sucking and butting (Jensen and Holm, 2003) was first observed, in addition to the characteristic body position described above. The end of a cross-sucking bout was defined by visible separation between actor and recipient calves for more than $3 \mathrm{~s}$.

For each cross-sucking event of $10 \mathrm{~s}$ or more, the start and end time, location, and identity of actor and recipient calf were recorded. Cross-sucking bouts of a shorter duration were disregarded to ensure true crosssucking events were distinguished from licking around the navel area.
Groups of calves were randomly allocated between 4 observers. Each group was watched by the same observer throughout to minimize observer effects. Following 2 repetitions of a sample video, inter- and intra-observer reliability were calculated. Data collection only commenced once the reliability was of a satisfactory level (Pearson's $r$ >0.9). This process was repeated, using the same sample video, halfway through each group to ensure data collection remained consistent for each observer as well as between observers.

Calves were observed continuously for $15 \mathrm{~h}$ (0800 to $2300 \mathrm{~h}$ ) on each recording day. Due to the fact that the timing of weaning depended upon the intakes of starter by each calf, weaning began and ended on different dates (and thus at different ages) for different calves. We observed the videotapes for $2 \mathrm{~d}$ during 5 age periods related to when the calves were weaned off milk (Table 1), with a total of $10 \mathrm{~d}$ per calf. All calves were watched on the first day without milk and the remaining days were selected to maximize the number of calves watched in each video. Individual calves were identified from video footage by their unique coat markings.

Daily intakes of hay and grain and estimated digestible energy intake for each calf were obtained from de Passillé and Rushen (2012).

Individuals were followed through to the end of their first lactation (dry off), and all incidences of udder damage (damaged teats or nonmilking quarters) and postpartum clinical mastitis, as reported by barn farm staff as part of normal farm procedure, were recorded. Somatic cell count at first milk test (tested at $23 \pm$ $9 \mathrm{~d}$ in milk) and 305-d mature-equivalent milk yield (305ME) was also recorded. The mature equivalent standardizes the lactation data to the level of yield that would have been attained by each cow if she had been a mature cow and calved in the month of highest calving frequency for her breed and is the standard measure used in North America to report production of dairy cattle.

\section{Organization of Data and Statistical Analysis}

Out of a total of 56 calves used in this experiment, 4 calves were excluded from analysis: one died, one had 
severe sickness, and 2 had incorrect early weaning resulting from problems with the automated milk feeder (affecting only these individuals).

For each cross-sucking event, the identities of both actor and recipient calves were recorded. For each of the 5 periods before and after weaning, cross sucking and feed data were averaged across the 2 observation days to give the mean daily duration for each period. Overall daily duration of cross sucking for each calf was calculated by averaging the daily durations for each period.

The distribution of daily durations of cross sucking was markedly skewed, and normality of data could not be achieved through transformation. Consequently, nonparametric tests were used to analyze data throughout. Data were described using median and interquartile values because these gave the best representation of the data. For data analysis, group effects were controlled by ranking calves' data within their group pens within each observation period, from those with the highest daily duration of cross sucking to lowest.

Out of the 52 calves with cross-sucking data, health data for the completed first lactation were available for 37 individuals (11 were sold and 4 died before completing their first lactation). Chi-squared analysis was used to test if heifers that were cross sucked in the final observation period, at 4 to 5 mo of age, were statistically more likely to develop mastitis during their first lactation. Kruskal-Wallis analysis was used to examine whether individuals which were cross sucked had higher SCC at first testing or lower milk production than those individuals that were not cross sucked in the late heifer barn observation period (4-5 mo of age).

All data were collated in Microsoft Excel 2010 (Microsoft Corporation, Redmond, WA), and Minitab 15 (Minitab Inc., State College, PA) and STATA 13.1 (College Station, TX) software packages were used for the analyses.

\section{RESULTS}

The daily duration of cross sucking was low (Figure 1a) with many calves not observed to cross suck during each period. However, the distribution of cross sucking between calves was markedly positively skewed. Although the majority of calves $(82.7 \%)$ cross sucked at least once, calves with an average daily duration in the 75 th percentile accounted for $75 \%$ of all observed cross-sucking events.

No overall difference was found between the observation periods in the daily duration of cross sucking (Kruskal-Wallis; $\mathrm{H}=1.38, \mathrm{df}=4, P=0.85$; Figure 1a). However, a pairwise comparison revealed a tendency toward an increase in cross sucking between calves $1 \mathrm{wk}$ after weaning (51-89 d of age) and 1 wk after moving to a new barn (92-120 d of age; Wilcoxon signed ranks; W $=138.0, P=0.08 ;$ median difference $=0.15 \mathrm{~min} / 15 \mathrm{~h}$ ) and a significant decrease in cross sucking $(\mathrm{W}=146.5$ $P=0.03$ ) between 1 wk after weaning (51-89 d of age) and after approximately 1 mo in the new barn (120-155 $\mathrm{d}$ of age, median difference $=-0.10 \mathrm{~min} / 15 \mathrm{~h}$ ).

The duration of cross sucking in the late heifer barn period was correlated with the duration of cross sucking in all preceding periods, especially with the duration of cross sucking during the early heifer barn period (Table 2). A large proportion of heifers which were observed cross sucking at 4 to 5 mo of age were
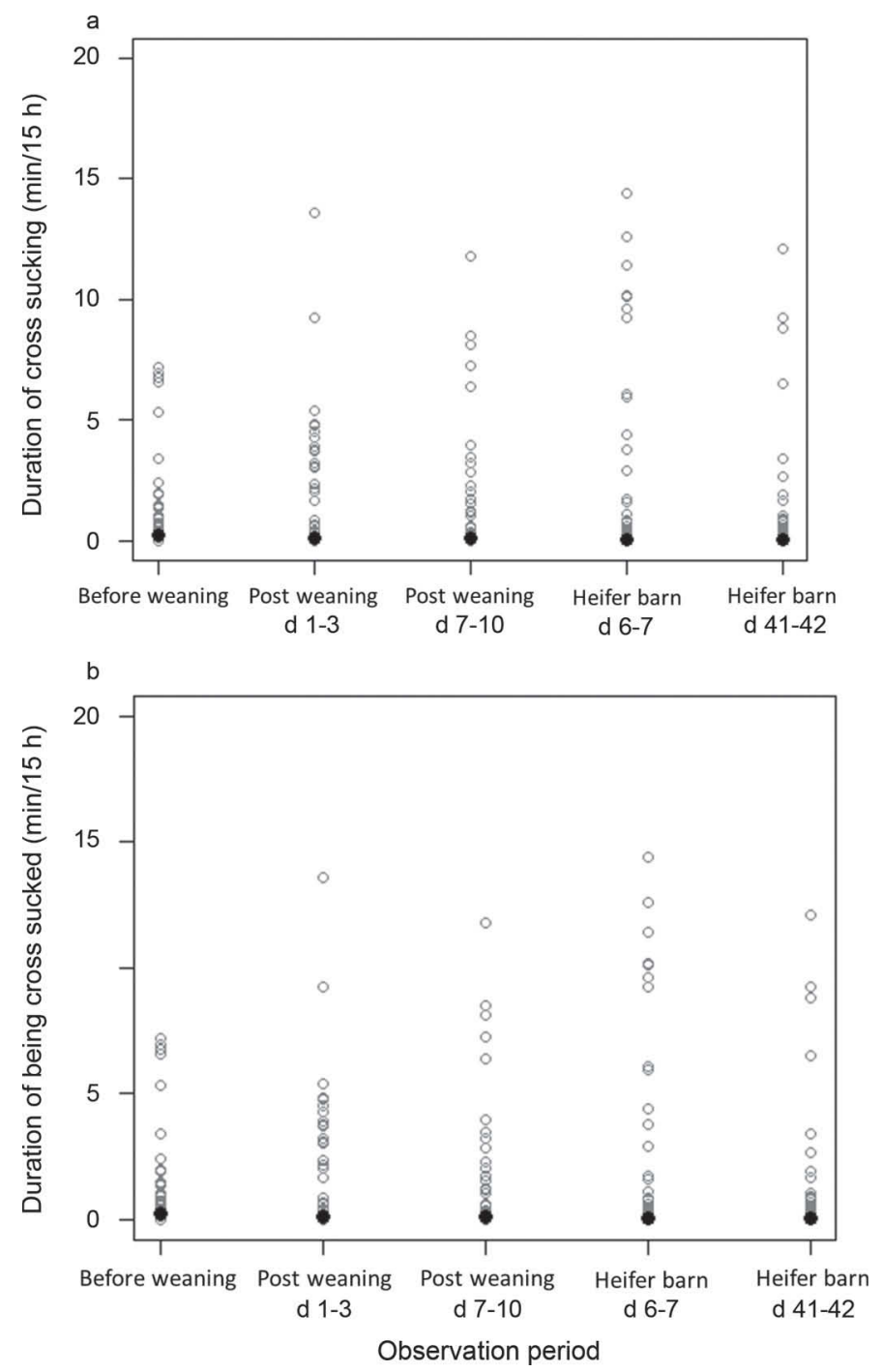

Figure 1. (a) Duration of cross sucking (min) across $15 \mathrm{~h}$ at each observation period $(\mathrm{n}=56)$. Open points represent individual calves, and solid circles represent medians. (b) Duration of being cross sucked at each observation period for all treatments pooled $(\mathrm{n}=56)$. Each open point represents an individual calf, and solid circles represent medians. 
Table 2. Spearman rank correlation between duration of cross sucking in heifer barn d 41 to 42 and other observation periods, data ranked within groups $(\mathrm{n}=52)$

\begin{tabular}{lcccc}
\hline & \multicolumn{4}{c}{ Period } \\
\cline { 2 - 5 } $\begin{array}{l}\text { Spearman } \\
\text { rank }\end{array}$ & Before & $\begin{array}{c}\text { Postweaning } \\
\text { d } 1-3\end{array}$ & $\begin{array}{c}\text { Postweaning } \\
\text { d 7-10 }\end{array}$ & $\begin{array}{c}\text { Heifer barn } \\
\text { d 6-7 }\end{array}$ \\
\hline Spearman $\mathrm{r}$ & 0.50 & 0.35 & 0.45 & 0.60 \\
$P$ & $<0.001$ & 0.01 & $<0.001$ & $<0.001$ \\
\hline
\end{tabular}

also observed cross sucking before weaning; of the 26 individuals cross sucking in the heifer barn, 19 were also cross sucking before weaning (73.1\%). However, out of the 22 calves never observed to cross suck before weaning, 7 individuals were found to cross suck at 4 to 5 mo of age (31.8\%).

No significant correlation was found between daily duration of cross sucking at 4 to 5 mo of age and grain intake, hay intake, or digestible energy intake during that period [Spearman $\mathrm{r}\left(\mathbf{r}_{\mathrm{s}}\right)<0.09 ; P>0.10$ ]. In addition, no correlation was found between cross sucking and weaning age or duration $\left(\mathrm{r}_{\mathrm{s}}<0.09 ; P>0.10\right)$.

Calves were not equally targeted as recipients of cross sucking; within each period only a few calves were observed being cross sucked for more than 5 min across $15 \mathrm{~h}$ (Figure 1b). No relationship was found between the duration of cross sucking and the duration of being cross sucked either before weaning $\left(\mathrm{r}_{\mathrm{s}}=0.16 ; P>0.10\right)$ or immediately after weaning $\left(\mathrm{r}_{\mathrm{s}}=0.15 ; P<0.10\right)$. One week after weaning calves which did more cross sucking were cross sucked more $\left(\mathrm{r}_{\mathrm{s}}=0.57 ; P<0.001\right)$ and this relationship remained after the groups were moved to the heifer barns (d 6-7: $\mathrm{r}=0.66 ; P<0.001$; d 41-42: $\left.\mathrm{r}_{\mathrm{s}}=0.50 ; P<0.001\right)$.

Calves did not cross suck indiscriminately; of calves cross sucking, $58.1 \%$ had a preferred partner (defined as a single recipient targeted for $>50 \%$ of an actor calf's recorded cross-sucking bouts). Although the majority of calves $(82.7 \%)$ were the target of cross sucking in at least one period, preferred recipients $(\mathrm{n}=17 ; 32.7 \%$ of all calves) account for $77.4 \%$ of all cross-sucking events. With the exception of one pair, reciprocal cross-sucking pairs were not observed before weaning (Table 3). In contrast, individuals cross sucking in the late heifer barn period appear to form reciprocal cross-sucking pairs, with almost all heifers being cross sucked the most by the heifer they most frequently sucked upon (Table 4).

Individuals that were cross sucked in the late heifer barn period (120-155 d of age) were not significantly more likely to have mastitis during their first lactation than those that were not cross sucked (Table $5 ; \chi^{2}=0.3$, $P=0.58)$. Damaged or nonfunctioning udder quarters were not observed in any cow. No significant difference was found between cross sucked and non-cross-sucked cows in the SCC levels recorded at first testing in their first lactation (Kruskal-Wallis; $\mathrm{H}=0.69, \mathrm{df}=1, P=$ 0.41 ). Additionally, no significant difference was found in production (305ME) between cows that were cross sucked postweaning and those that were not $(\mathrm{H}=0.35$, $\mathrm{df}=1, P=0.56)$.

\section{DISCUSSION}

Our results show that cross sucking may persist in older, weaned animals as the result of the formation of reciprocal cross-sucking pairs. The overall level of cross sucking observed at 4 to 5 mo of age was low and

Table 3. Calves with $\geq 3$ cross-sucking events and preferred partners ( $>50 \%$ of bouts) in the period before weaning $(\mathrm{n}=10)$

\begin{tabular}{clclc}
\hline Pen no. & Calf no. & $\begin{array}{c}\text { Frequency of cross- } \\
\text { sucking bouts }\end{array}$ & $\begin{array}{l}\text { Most frequently } \\
\text { sucked calf }\end{array}$ & $\begin{array}{c}\text { \% of events with most } \\
\text { frequently sucked calf }\end{array}$ \\
\hline 1 & H60 & 5 & H61 & 80 \\
& H65 & 7 & H66 & 71.4 \\
3 & H66 & 6 & H65 & 83.3 \\
& H79 & 5 & H78 & 100 \\
4 & H81 & 4 & H78 & 100 \\
& H83 & 4 & H99 & 77.8 \\
7 & H100 & 9 & H98 & 75 \\
8 & H102 & 4 & H1047 & 66.6 \\
\hline
\end{tabular}


Table 4. Calves with $\geq 3$ cross-sucking events and preferred partners ( $>50 \%$ of bouts) d 41 and 42 in the heifer barn $(\mathrm{n}=7)$

\begin{tabular}{clclc}
\hline Pen no. & Calf no. & $\begin{array}{c}\text { Frequency of cross- } \\
\text { sucking bouts }\end{array}$ & $\begin{array}{l}\text { Most frequently } \\
\text { sucked calf }\end{array}$ & $\begin{array}{c}\text { \% of events with most } \\
\text { frequently sucked calf }\end{array}$ \\
\hline 1 & H65 & 8 & H66 & 100.0 \\
& H66 & 4 & H65 & 100.0 \\
2 & H67 & 20 & H71 & 55 \\
4 & H71 & 3 & H67 & 100.0 \\
5 & H102 & 4 & H100 & 66.7 \\
& H123 & 4 & H123 & 75.0 \\
\hline
\end{tabular}

${ }^{1} \mathrm{H} 100$ was only observed to cross suck twice within this period but in both cases H102 was the recipient.

was mainly performed by a few individuals. The cross sucking observed between heifers in this experiment did not appear to be detrimental to udder health.

Cross-sucking pairs appeared to develop over time. In the last 3 observation periods after weaning, calves that did the most cross sucking tended to be those that were cross sucked the most. However this relationship was not found before or immediately after weaning. With the exception of 2 calves, pairs of preferred partners (where a calf is cross sucked the most by its own preferred partner) were not apparent before weaning, but by 4 to 5 mo of age, pairs of mutually cross-sucking calves were observed and accounted for most of the cross sucking that occurred.

It was important to see if we could predict which individuals would be cross sucking in the final observation period because cross sucking is thought to be most detrimental to recipients as animals mature, where it has been identified as a risk factor for udder damage and mastitis (Lidfors and Isberg, 2003). The findings of Lidfors and Isberg (2003) should be taken with caution, however; this study was based on data obtained from a phone questionnaire and not direct observations of the cattle and thus could simply be a reflection of producers' belief in a link between cross sucking and mastitis. We found a significant correlation between duration of cross sucking by calves 2 mo after weaning with the amount done before and immediately after weaning. However, a third of the calves that were not observed to cross suck before weaning were found to cross suck in the late heifer barn period, so early cross sucking is not a strong predictor of how much cross sucking a calf will do months after weaning.

Both early and abrupt weaning are known to increase cross sucking (Nielsen et al., 2008; Sweeney et al., 2010) as calves' rumens are likely to be less developed and may struggle to adjust to the dietary shift. In this study, however, we found no significant relationship between cross sucking in the final observation period and age at start or end of weaning or weaning duration. Roth et al. (2008) reported calves weaned by age (milk reduction began at 8 wk of age and was completed at 11.5 wk of age) had a significantly higher daily duration of cross sucking in comparison to calves weaned according to voluntary grain intake. Weaning according to voluntary grain intake may allow calves capable of meeting nutritional requirements on solid feed to be weaned at an earlier age while permitting slower maturing individuals to be weaned later, potentially reducing emergence of abnormal behaviors (Roth et al., 2008).

A useful approach to understand the persistence of cross sucking is to examine why calves tolerate being cross sucked. Keil and Langhans (2001) noted that 72 to $76 \%$ of attempted cross-sucking events were terminated by the recipient calf before sucking movements had time to take place. Calves do not cross suck randomly, rather cross sucking is typically focused on 1 or 2 preferred recipients within a group and it may be because these calves are more tolerant of this behavior (Laukkanen et al., 2010). We found a positive correlation across calves in the duration of cross sucking and of being cross sucked supporting previous research (Keil

Table 5. Health and production measures for cows that were not cross sucked, cross-sucked cows ( $\geq 1$ event), and the subset of cows had formed cross-sucking pairs at 4 to 5 mo of age

\begin{tabular}{lccc}
\hline Item & Not cross sucked & Cross sucked & Preferred partners \\
\hline SCC (cells/L) & $189.75 \pm 473.39(\mathrm{n}=24)$ & $148.5 \pm 237.37(\mathrm{n}=19)$ & $79.83 \pm 48.85(\mathrm{n}=6)$ \\
Clinical mastitis (\% of cows) & $17(\mathrm{n}=23)$ & $31(\mathrm{n}=16)$ & $25(\mathrm{n}=4)$ \\
305ME (L) & $9,306.67 \pm 1,520.66(\mathrm{n}=21)$ & $9,373.57 \pm 1,038.83(\mathrm{n}=14)$ & $10,103.33 \pm 315.65(\mathrm{n}=3)$ \\
\hline
\end{tabular}

${ }^{1} \mathrm{SCC}$ reported for all cows present at first milk test; clinical mastitis reported for all cows completing $\geq 100 \mathrm{~d}$ of lactation; 305-d mature-equivalent milk yield (305ME) reported for cows completing first lactation. 
and Langhans, 2001; de Passillé et al., 2011). Although calves within the current study cross suck upon 1 or 2 individuals at each observation period, fixed, reciprocal cross-sucking pairs only become apparent in the late heifer barn period, once calves were approximately 4 to 5 mo old. The heifers in this study were housed in stable groups from the first week of life until they reached breeding age (approximately $18 \mathrm{mo}$ old) and observations at 8 mo of age, for the purposes of another experiment, confirmed the fidelity of established crosssucking pairs. In contrast, formation of cross-sucking partners was not found by Špinka (1992), who suggested the positive correlation between cross sucking and being cross sucked was due to social facilitation rather than pair formation.

In free living cattle, weaning from milk is achieved by the mother's refusal to allow continued nursing (Śpinka, 1992). This may account for why cross-sucking behavior continues into adulthood, provided the calf is able to find a recipient who will not resist being cross sucked. Calves may be more accepting of being cross sucked if they themselves perform this behavior and formation of reciprocal cross-sucking pairs (where a calf is cross sucked the most by its own preferred partner) may explain why this behavior persists in certain calves. Separation of older established cross-sucking pairs may offer a practical approach to stopping this behavior. Given the rarity of this behavior (only 8 calves cross sucked more than 3 times in the last observation period and of those 6 were part of a cross-sucking pair) and the apparent fidelity of cross-sucking pairs, it is unlikely they would be able to establish another cross-sucking partnership.

Cross sucking displays many features characteristic of a stereotypic behavior, which have been defined as repetitive actions that are fixed in form and orientation and serve no obvious function (Garner, 2005). Three major developmental stages of stereotypies can be distinguished: increasing performance, increasing invariance, and emancipation from original eliciting stimuli (Würbel, 2010). It has been proposed that, in individuals that continue cross sucking after weaning, this behavior becomes habitual and divorced from the underlying factors which could have been responsible for their initial development (Keil et al., 2001; de Passillé et al., 2011). Although the majority of calves cease this behavior after weaning, those continuing in later stages have been found to increase their daily duration of cross sucking (de Passillé et al., 2011). Furthermore, the establishment of fixed actor-recipient pairs found in the later heifer barn period may be an example of increasing invariance of the pattern of this behavior.

This study is the first to follow individual heifers through their first lactation and examine whether involvement in cross sucking increased likelihood of developing mastitis. Being cross sucked did not appear to influence likelihood of developing mastitis in the first lactation in comparison to individuals who were not cross sucked. Additionally, no incidence of udder damage was observed nor was milk production during first lactation significantly less in cross-sucked individuals. These findings are at odds with the often touted claim that cross sucking leads to mastitis and udder damage in heifers (Špinka, 1992; Debrecéni and Juhas, 1999; Keil et al., 2000). Cross sucking occurred mainly between reciprocal pairs, and because a heifer was generally cross sucking upon one other individual, it seems an unlikely route for bacteria to be transferred between the teats of infected and uninfected individuals. The level of cross sucking observed in this study was low and it is conceivable that more intense cross sucking activity could potentially represent a health risk to recipients. It may be that taking steps to reduce development of cross sucking, as is done in this facility (for example, ad libitum milk available via a teat), results in only occasional cross sucking, which does not represent a threat to udder health for the recipient.

\section{CONCLUSIONS}

Cross sucking may begin at a young age and develop into a habit over time, persisting within pairs of preferred partners. Although the reason why some calves cross suck and others do not when reared under the same conditions remains unclear, the pairs of reciprocally cross sucking heifers found in the current study offer an explanation why this behavior persists in adult cows. Furthermore, the findings of this study suggest that low levels of cross sucking do not appear to increase likelihood of mastitis or udder damage in recipients.

\section{ACKNOWLEDGMENTS}

The authors thank J. P. Parent, Ruby Wong, and Jason and Gosia Zdanowicz. The authors also thank the staff at the Ethology Laboratory (Agriculture and Agri Food Canada, Agassiz, BC, Canada) and the dairy staff (University of British Columbia, Agassiz, BC) for their invaluable help. Funding was provided by Agriculture and Agri-Food Canada and the Natural Sciences and Engineering Research Council of Canada (both in Ottawa, ON, Canada).

\section{REFERENCES}

de Passillé, A. M., F. T. Borderas, and J. Rushen. 2011. Cross-sucking by dairy calves may become a habit or reflect characteristics of in- 
dividual calves more than milk allowance or weaning. Appl. Anim. Behav. Sci. 133:137-143.

de Passillé, A. M., and J. Rushen. 2012. Adjusting the weaning age of calves fed by automated feeders according to individual intakes of solid feed. J. Dairy Sci. 95:5292-5298.

Debrecéni, O., and P. Juhas. 1999. Milk-sucking in dairy cattle in loose housing in Slovakia. Livest. Prod. Sci. 61:1-6.

Garner, J. P. 2005. Perseveration and stereotypy-Systems-level insights from clinical psychology. In Stereotypic Animal Behaviour: Fundamentals and Applications to Welfare. 2nd ed. J. Rushen and G. Mason, ed. CAB International, Wallingford, UK.

Jensen, M. B., and L. Holm. 2003. The effect of milk flow rate and milk allowance on feeding related behaviour in dairy calves fed by computer controlled milk feeders. Appl. Anim. Behav. Sci. 82:87-100.

Jung, J., and L. M. Lidfors. 2001. Effects of amount of milk, milk flow and access to a rubber teat on cross-sucking and non-nutritive sucking in dairy calves. Appl. Anim. Behav. Sci. 72:201-213.

Keil, N. M., L. Audigé, and W. Langhans. 2000. Factors associated with intersucking in Swiss dairy heifers. Prev. Vet. Med. 45:305323.

Keil, N. M., L. Audigé, and W. Langhans. 2001. Is intersucking in dairy cows the continuation of a habit developed in early life? J. Dairy Sci. 84:140-146.
Keil, N. M., and W. Langhans. 2001. The development of intersucking in dairy calves around weaning. Appl. Anim. Behav. Sci. 72:295308

Laukkanen, H., J. Rushen, and A. M. de Passillé. 2010. Which dairy calves are cross-sucked? Appl. Anim. Behav. Sci. 125:91-95.

Lidfors, L. M. 1993. Cross-sucking in group-housed dairy calves before and after weaning off milk. Appl. Anim. Behav. Sci. 38:15-24.

Lidfors, L. M., and L. Isberg. 2003. Intersucking in dairy cattle-Review and questionnaire. Appl. Anim. Behav. Sci. 80:207-231.

Nielsen, P., M. B. Jensen, and L. M. Lidfors. 2008. Milk allowance and weaning method affect the use of a computer controlled milk feeder and the development of cross-sucking in dairy calves. Appl. Anim. Behav. Sci. 109:223-237.

Roth, B. A., E. Hillmann, M. Stauffacher, and N. M. Keil. 2008. Improved weaning reduces cross sucking and may improve weight gain in dairy calves. Appl. Anim. Behav. Sci. 111:251-261.

Špinka, M. 1992. Intersucking in dairy heifers during the first two years of life. Behav. Processes 28:41-49.

Sweeney, B. C., J. Rushen, D. M. Weary, and A. M. de Passillé. 2010. Duration of weaning, starter intake, and weight gain of dairy calves fed large amounts of milk. J. Dairy Sci. 93:148-152. 